\title{
A "escrita de si" na formação em Educação Física
}

\author{
Flávio Soares Alves* \\ Yara Maria de Carvalho** \\ Romualdo Dias***
}

\begin{abstract}
Resumo: O objetivo deste ensaio é criar um campo de discussões sobre a "escrita de si" no contexto da formação em Educação Física, reconhecendo o exercício de escrita como um modo potente de captação e reinvenção do que escapa à ordem do conhecimento e que, ao mesmo tempo, exige do pensamento pensar a consistência dos encontros que atravessam os processos de formação profissional. Deste ponto, interessa tangenciar as demandas que ficam excluídas no discurso da formação, a saber: as sensibilidades, reconhecendo-as como expressões de um "conhecimento encarnado". Para além das competências teóricas, a "escrita de si" ajuda a edificar uma compreensão mais profunda da formação profissional, não porque dispara um discurso sobre a prática, mas por dar vazão à escrita das intensidades forjadas nos encontros entre conhecimentos e práticas.
\end{abstract}

Palavras-chave: Educação Física. Conhecimento. Atuação profissional. Competências.

\section{INTRODUÇÃo}

Em tempos de ascensão do tecnicismo os cursos de formação, não raras vezes, concentram seus esforços no ensino de aspectos procedimentais que capacitem os sujeitos a lidar com certo sistema de produção. É preciso assegurar o domínio de um "saber como", sem o qual a busca pela formação parece não ter sentido.

\footnotetext{
*Escola de Educação Física e Esportes da Universidade de São Paulo (USP). São Paulo, SP, Brasil. E-mail: flavio.salves@usp.br

**Escola de Educação Física e Esportes Universidade de São Paulo. (USP). São Paulo, SP, Brasil. E-mail: yaramc@usp.br

***Departamento de Educação. Universidade Estadual Paulista Júlio de Mesquita Filho (UNESP). Rio Claro, SP, Brasil. E-mail: diasro@terra.com.br
} 
No campo específico, muitos cursos de final de semana - rápidos e intensivos - que se fixam nas modalidades esportivas, no treinamento, na atividade física e nas técnicas corporais voltadas para a "boa forma" e o mercado do fitness convencem o futuro profissional de que a competência teórica que provêem pode dar conta do espaço da intervenção. Assim, cheio de certezas, o profissional de Educação Física se lança ao exercício profissional acreditando que sabe como o corpo funciona; os métodos mais adequados para determinada prática; associar objetivos, procedimentos e resultados no processo de avaliação. Nesta perspectiva, entende-se formação como aquisição de conhecimentos técnicos/abstratos para a atuação do profissional.

As relações entre saberes e práticas, no entanto, extrapolam os domínios da competência teórica adquirida. O intempestivo atravessa a ordem das relações por vir, colocando profissional, estudante, saberes, práticas e instituições face ao imponderável.

Assim, a formação precisa considerar e capacitar o aprendiz a lidar com as diferentes formas de conhecer, pensar e fazer em jogo na formação profissional. É no espaço onde este jogo se instala que a formação é colocada à prova, pois expõe o futuro profissional frente às circunstâncias situacionais e moventes que o cercam. Nesse sentido, a formação - entendida como campo que provê a aquisição/ transmissão de conhecimentos - muitas vezes não alcança essas intensidades que gostaríamos de enfatizar aqui.

Para ampliar o alcance e impacto da formação, reiteramos, é preciso colocar as diversas formas de conhecer em jogo: trata-se, portanto, de aceitar o desafio de encarar os encontros com o imponderável, que hão de vir, com toda potência lúdica e inventiva que podem mobilizar. O futuro profissional aceita os desafios deste jogo quando se lança à prática dos estágios, ao diálogo com as disciplinas de formação - curriculares e extracurriculares - e nos exercícios de pesquisa.

Considerando que a formação, de modo geral, se sustenta sobre os pilares do ensino, da pesquisa e da extensão é preciso correr os riscos de experimentar outros modos de articular essas frentes. $\mathrm{O}$ 
que observamos é que as iniciativas buscando aproximação entre esses pilares muitas vezes se conformam em reiterar uma ordem conceitual vigente, descartando o potencial de transgressão que carregam, em função de uma política acadêmica que tudo quer dobrar sobre os termos do conhecimento teórico-formal ${ }^{1}$. Acontece que nesse jogo entre produção de saberes e prática, não se trata apenas de conhecer, mas antes, de experimentar as profundidades que atravessam e qualificam a pesquisa, o ensino e a extensão.

Confundir conhecimento com experimentação é abrir mão de uma consistência furtiva, que escapa ao conhecimento e nos afeta em profundidade ${ }^{2}$, colocando-nos frente às vicissitudes do sentir.

O leitor pode estar reclamando por mais elementos que "iluminem" o que se esconde nesta escrita. Seguiremos, então, por introduzir o indevido: forçá-lo a pensar nos seus próprios exemplos frente às idéias aqui levantadas.

O que interessa é lembrar que ensino, pesquisa e extensão são espaços reservados ao jogo - aos encontros - onde o conhecimento é posto à prova, forçando o pensamento a pensar resoluções que dêem conta deste jogo instalado.

\section{Os ELEMENTOS QUE ESCAPAM AO CONHECIMENTO}

Ao mobilizar o conhecimento, os desafios elevam o encontro para além dos conceitos do entendimento já acomodados e determinados por experiências anteriores. Tal mobilização não acontece sem um olhar prospectivo, ou seja, um olhar orientado para os eventos sempre episódicos que se instalam toda vez que a

\footnotetext{
${ }^{1}$ A partir da leitura de Imbernón (2010) é possível observar que as novas demandas da formação profissional exigem certo ultrapassamento desta política acadêmica pautada pelo conhecimento objetivo e disciplinar, que cabe sob os termos do conhecimento teórico-formal. Tais demandas, no entanto, não devem prescindir deste conhecimento. Trata-se, antes, de deslocá-lo através da necessária abertura à aprendizagem da relação e da convivência entre as partes de constituem o campo da formação.

${ }^{2}$ Segundo Deleuze (2006, p. 324). a profundidade é "[...] a que vem do âmago das coisas, em diagonal, e que reparte os vulcões, para reunir uma sensibilidade em ebulição a um pensamento que 'troveja em sua cratera."
}

Movimento, Porto Alegre, v. 17, n. 02, p. 239-258, abr/jun de 2011. 
formação nos lança frente às relações por vir no encontro. Aquele que direciona sua atenção à espera do que há de vir coloca o conhecimento à prova, como desdobramento desta atitude aventureira e sua percepção é aguçada, favorecendo o alcance daquilo que não se deixa capturar pelo conhecimento.

O que escapa aos termos do conhecimento?

O corpo e as sensibilidades que o atravessam!

Não é difícil atestar esta habilidade de esquiva dada ao campo das sensibilidades. $\mathrm{O}$ que sabemos e produzimos sobre o corpo no campo acadêmico denominado Educação Física? Sabemos de fisiologia do exercício, biomecânica, esquemas motores, capacidade de aprendizagem e controle motor; comportamentos psicológicos, registros históricos, filosóficos, antropológicos e institucionais, suas adequações na escola, no clube, na academia. Mas e suas sensibilidades? Onde estão? Certamente fora do discurso das ciências, até porque não se faz ciência - na sua concepção moderna - sem antes prescindir de tudo o que a torna equívoca e indeterminada (ALVES, 2009). Como metrificar um afeto, ou a intensidade do gosto, do prazer e do lúdico? A ciência pode até forjar respostas a estas perguntas, mas não sem antes abdicar daquilo que consiste as sensibilidades.

Poderíamos então dizer: a sensibilidade está fadada a escapar indefinidamente da ordem do dizível. Estranhamente este proposição não se sustenta, pois a escrita que se deixa levar pelo intempestivo recolhe a sensibilidade, não para inscrevê-la como verdade absoluta, mas para permitir a composição: a invenção do encontro no campo da escrita.

Quando nos abandonamos no atravessar do intempestivo, deixando vir linhas de pensamento sem conduzi-las de modo regular e ordinal, entregamo-nos a um exercício transcendente da sensibilidade, onde a imaginação se eleva a um nível onde só apreende 
aquilo que não pode ser apreendido do ponto de vista do senso comum e que, portanto, não se recalca sobre o exercício empírico da sensibilidade (DELEUZE, 2006).

Segundo Deleuze (2006) a escrita mobilizada neste exercício transcendente da sensibilidade se libera das coerções da consciência e impulsionada pela imaginação se aventura no pensamento involuntário, forjando impressões verbais de uma sensibilidade em atravessamento.

É nesse sentido que a formação encontra acesso a este exercício transcendente da sensibilidade quando instiga e promove experiências voltadas para a "escrita de si".

O objetivo deste ensaio é criar um campo de discussões sobre a "escrita de si" no contexto da formação em Educação Física, reconhecendo este exercício de escrita como uma forma de mobilizar os sujeitos na captação daquilo que escapa à ordem do conhecimento - a sensibilidade - e que força o pensamento a pensar a consistência dos encontros que atravessam os processos de formação.

As expressões escritas que derivam da sensibilidade dão testemunhos de um conhecimento incrustado nos músculos, nos nervos, no esqueleto, nos órgãos ao longo de todo o processo do ser humano na constituição e invenção de si.

A escrita aberta a estas expressões possibilitará mapearmos os processos que movimentam o jogo entre teoria e prática - os encontros, os entres - revelando o implicado que introduz a marca do tempo e das vivências no traço da escrita daquele que se encontra em formação.

A "escrita de si" como experiência que força o sujeito a pensar o espaço e o tempo do encontro, campo no qual colocamos a formação profissional em pauta. 


\section{A "ESCRTAA DE SI" COMO EXERCícIO de FORMAÇÃo}

Segundo Foucault, (2006, p. 145) a escrita de si não atua somente sobre os atos, "[...] porém, mais precisamente sobre o pensamento" e completa: "[...] a escrita constitui uma experiência e uma espécie de pedra de toque: revelando os movimentos do pensamento $[\ldots]^{\text {"3. }}$.

Na leitura de Foucault (2006), a antiguidade clássica ensina que a "escrita de si" não é exatamente uma prática descritiva que compreende um registro prescritivo dos atos vividos, mas, antes, um exercício que movimenta o pensamento, forçando-o a pensar a experiência vivida.

O que isto tem a ver com formação profissional? Formação é campo no qual professor e aluno se implicam. Em meio a esta implicação, temos então um encontro que dispara a produção da escrita. O que é possível dizer sobre este encontro? Ele captura tudo aquilo que se dobra aos termos do conhecimento: as técnicas de ensino, os métodos de intervenção e os procedimentos que regulam a relação mestre-aprendiz. Todavia, ousamos perguntar: o que vai além do possível? Os movimentos do pensamento que dão testemunho de um jogo instalado no encontro entre o dizer e o fazer, o conhecimento e a prática, algo só captado nos registros da "escrita de si".

Temos na "escrita de si", portanto, um exercício de reflexão que amplia a formação, pois extrapola a ordem do registro possível e alcança o registro das profundidades forjadas no encontro. E, sem a abertura a estas profundidades, o conhecimento não se implica no corpo e, portanto, não é colocado em movimento.

Segundo Foucault: "[...] nenhuma técnica, nenhuma habilidade profissional pode ser adquirida sem exercício" (2006, p. 146). Pensar em formação profissional a partir desta leitura implica em pensá-la

\footnotetext{
${ }^{3} \mathrm{~A}$ partir de um texto de Atanásio, pensador da cultura greco-romana, Foucault (2006) faz uma análise da importância da escrita na cultura filosófica de si constituída precisamente antes do cristianismo, no período do alto império nos séculos I e II.
} 
como um "treino de si por si mesmo" que transforma o exercício da formação numa prática estética, isto é, um campo de lapidação de si, como arte de viver - algo que a cultura filosófica de si chamava de technê tou biou (FOUCAULT, 2006, p. 146). É justamente nos domínios desta formação pensada enquanto campo de lapidação que os exercícios da "escrita de si" ganham força, pois funcionam como dispositivos que reforçam as pontes que o próprio sujeito forja ao se implicar no campo da formação que escolheu tomar para si.

\section{OS ENCONTROS COMO DISPARADORES DA ESCRITA}

Antes de se entregar a um exercício de escrita é preciso ser afetado, ou seja, é preciso se esgueirar nas tramas do por vir da experiência. A prática do profissional coloca-o literalmente em movimento na relação que estabelece com seus alunos. Um sujeito em processo de formação ainda não se vê à beira da atuação profissional, mas pode se colocar em movimento nas infinitas possibilidades de relação que pode trilhar seja nos estágios supervisionados, nas diferentes estratégias que aproximam ensino e serviço $^{4}$, nas experiências didáticas, ou ainda nos exercícios de pesquisa e intervenção.

É no campo onde estas relações acontecem que se instala o encontro, ou seja, o espaço-tempo no qual profissional e aluno se implicam. É no encontro que a competência teórica adquirida na formação é colocada à prova; e, é também no encontro que o sujeito se vê frente ao plano intensivo das forças e se vê mobilizado ou não a jogar com elas.

Segundo Deleuze e Parnet (1998), no plano de forças o que existe é um plano concreto de intensidades e singularidades, que suspendem as formas num interstício que se sustenta no ato, e

\footnotetext{
${ }^{4}$ O Programa de Educação pelo Trabalho para a Saúde (PET-SAÚDE) pode ser um exemplo. É um programa regulamentado pela Portaria Interministerial № 421, de 03 de março de 2010, inspirado no Programa de Educação Tutorial - PET, do Ministério da Educação.
}

Vovimento, Porto Alegre, v. 17, n. 02, p. 239-258, abr/jun de 2011. 
somente no ato em que as formas são requisitadas no plano das intensidades. O que seriam estas formas? Dentro do contexto aqui suscitado, podemos considerar estas formas como o conhecimento teórico adquirido na formação. É este conhecimento que aparece como elemento, sem o qual não se capacita os sujeitos dentro de certo sistema de produção.

As formas constituem-se naquilo que o pensamento representativo reconhece como objetos do conhecimento. A ascensão à dimensão movente da realidade - esta constituída no plano de forças - implica em afetar as condições de gênese dos objetos. Isto significa um desvio do pensamento representativo que domina o plano das formas. Só é possível alcançar e acompanhar o plano de forças através da desestabilização das formas, algo possível quando o sujeito se lança à imprevisibilidade dos acontecimentos, na dimensão do por vir dos encontros 5 .

Uma vez entregue ao devir da experiência, a consciência, entendida como domínio da intencionalidade, dissolve-se, ampliando suas margens, elevando a consciência para outros estados, alheios ao poderio indolente da razão suficiente ${ }^{6}$. Neste estado elevado da consciência, só localizado no plano intensivo onde as forças se põem em relação, a experiência da escrita consegue tangenciar o sensível, transformando-o em prosa, sem com isto resumir a consistência lá emergente. Para tanto, é preciso se desviar da tendência ao discurso impositivo, que tudo quer dobrar sob a legitimidade que lhe é conferida pela razão suficiente.

\footnotetext{
${ }^{5}$ Convém salientar, no entanto, que o plano das formas e o plano das forças não se opõem, mas constroem entre si recíprocas relações que asseguram múltiplos cruzamentos (PASSOS et al, 2009)

${ }^{6} \mathrm{~A}$ razão suficiente é o domínio da consciência no qual vigora o plano das formas (logos). A razão suficiente invoca a identidade do conceito - tratando-a como princípio - tanto para explicar quanto para compreender aquilo que é submetido à sua apreciação (DELEUZE, 2006, p. 377382; DELEUZE; PARNET, 2004). O pensar como exercício do pensamento mediado sob os domínios da razão suficiente implica em pensar a partir do campo das representações, onde a operação intencional consciente descarta aquilo que foge às suas possibilidades de explicação e compreensão para enquadrar o pensamento, dando-lhe um fundamento que define as condições da experiência possível.
} 
Como operar o traço desta escrita alheia ao discurso impositivo? É preciso amainar as pretensões de uma resposta cabal a esta questão. Não há um procedimento específico, sistêmico e linear que resolva o dilema dos rumos do por vir da escrita, pois quando o sensível a atravessa, o desarranjo que promove dissolve qualquer procedimento previamente alinhado para conduzi-la. Assim, a escrita se torna um exercício artístico que não pode ser controlado de antemão. O máximo que podemos fazer é apresentar pistas que inspirem o escritor à busca das sensibilidades que só ele tem acesso.

\section{Pistas para a "escrita de sI" - No rastro do plano intensivo DAS FORÇAS}

Segundo Passos, Kastrup e Escóssia (2009, p.13) pistas "[...] são como referências que concorrem para a manutenção de uma atitude de abertura ao que vai se produzindo e de calibragem do caminhar [...]". É a partir deste entendimento que nos lançamos ao texto que se engendra.

Através da "escrita de si" é possível reunir, na forma de relatos, informações objetivas e impressões furtivas. Estas impressões não forjam um texto interpretativo e a presença de dados objetivos, também não constituem uma análise objetiva. Entre a objetividade e a subjetividade, o relato se mantém suspenso, atento à captação daquilo que se dá no plano intensivo das forças: espaço potencial onde o encontro se instala.

Nesta escrita imersa no plano intensivo das forças o escritor inscreve aquilo que julga importante, mas, à medida que se deixa levar por um movimento espontâneo de explicitação ${ }^{7}$ das experiências vividas, deixa se inscrever também algo mais precioso: dados que permaneciam até então num nível inconsciente e pré-refletido.

Segundo Passos e Kastrup (2009, p. 69-70) o alcance destes dados não se faz sem certo recolhimento "[...] cujo objetivo é

\footnotetext{
${ }^{7}$ Segundo Passos e Kastrup, explicitação designa "[...] o ato de trazer à consciência uma dimensão pré-reflexiva da ação." (PASSOS et al, 2009, p. 83)
} 
possibilitar um retorno à experiência do campo, para que se possa então falar de dentro da experiência e não de fora, ou seja, sobre a experiência."

A "escrita de si", portanto, não se faz sem uma tomada de fôlego, que reporta o escritor a um passo para trás, para o campo intensivo das forças, onde se encharca dos afetos que lhe acometeram em meio ao curso dos acontecimentos e se despoja no traço de um registro forjado num campo implicacional.

Este movimento da escrita não é um exercício fácil e não está garantido de antemão, pois requer um aprendizado e uma atenção permanente, sem os quais o escritor se rende à sedução de uma política cognitiva que ajusta os rumos da escrita em direção a busca de soluções e regras forjadas fora do campo implicacional ${ }^{8}$.

Novamente reiteramos que não há uma forma previamente estruturada que guia a produção da "escrita de si". A única prerrogativa que se institui é a abertura do escritor aos movimentos da experiência que mobilizou este exercício. Segundo Lourau, (1993, p. 72) os textos que derivam destes movimentos "[...] realizam restituições insuportáveis à instituição científica." Para tangenciar os movimentos que atravessam esta escrita, o escritor precisa se deixar afetar, sem apego pelos acontecimentos vivenciados lá, no momento mesmo em que o encontro se dá como evento.

Assim, nos rastros de uma visibilidade implicada nas experiências vividas, a figura do escritor como observador externo e neutro se dissolve no rumo por vir das relações tramadas e transformadas em palavras no corpo da escrita. Nestes termos, a escrita coloca lado a lado conhecimento e devir: texto e fora-texto. Ambos, co-emergem no traço da escrita deixando indícios de uma sensibilidade em atravessamento. E, a "escrita de si" alimenta-se deste atravessamento.

\footnotetext{
${ }^{8}$ Segundo Lourau (1993) campo implicacional consiste numa dinâmica relacional transpassada por um jogo intenso de forças que contagia as partes envolvidas na relação, dissolvendo a condição dual que as localiza na oposição entre dois agentes. A implicação, portanto, dissolve as oposições, em função da imersão dos opositores num plano intensivo que os atravessa.
} 


\section{Por uma ATENÇão sem foco na "ESCRITA de sI"}

A "escrita de si" exige um movimento de rastreio que desloque a atenção para o canal onde se encontra a profundidade dos acontecimentos. Num primeiro momento, sob os domínios de uma atenção seletiva e focal. Certo daquilo que quer procurar, o foco da atenção procura, incauto, por um caminho que localize a profundidade dos acontecimentos, todavia, na varredura que descerra, nada encontra. Isto acontece porque, neste caso, a atenção seletiva não alcança aquilo que se propõe procurar: a sensibilidade que lhe escapa ligeira e furtiva.

Segundo Kastrup (2009, p. 35-36) o nível atencional seletivo é um grande obstáculo à descoberta, pois fecha o foco por sobre aquilo que supostamente já pretendia focar antes mesmo de olhar. Sob os domínios de uma atenção seletiva, portanto, a escrita é movida pelas certezas que o escritor leva consigo, assim funciona como registro de reiteração e reconhecimento de um conhecimento já edificado. Não é, pois, sobre estes domínios restritos da atenção que a "escrita de si" encontra um canal de expressão. Reconhecer esta inviabilidade frente aos domínios da atenção seletiva já é um primeiro passo.

Depois de reconhecer esta inviabilidade é o momento de um segundo rastreio, menos pretensioso e mais aberto ao movimento perceptivo que não sabemos muito bem por onde irá passar. Nesta abertura, a consciência, entendida como domínio de intencionalidade, vai perdendo terreno, em função da invasão de uma atenção flutuante, canal no qual o atravessar das sensibilidades se intensifica (KASTRUP, 2009).

Nos domínios de uma atenção que flutua, ao sabor dos acontecimentos por vir, a escrita é atravessada pelo intenso e envolvida, deixa vir linhas de pensamento, compondo as palavras tal como um artista compõe sua arte: entregue à aventura de uma obra.

Deleuze (2006) dá pistas que ajudam a manter a atenção sintonizada neste caminho flutuante, quando alerta sobre o perigo da explicação excessiva. Ao se esgueirar nas tramas de um texto 
explicativo o escritor rompe com o espaço da experiência para, de um lado, elevar a escrita forjada ao estado de objeto e, de outro, elevar o esforço da escrita ao direito de uma autoria: a dele próprio.

O autor da escrita faz valer seu poder de enunciação ao lançar mão de palavras de ordem. Segundo Deleuze e Guattari (1995), as palavras de ordem conferem ao enunciado força de obrigação e, como efeito, aprisionam a realidade em um sentido dado. É aí que se engendra a explicação excessiva.

Para romper com as palavras de ordem Deleuze (2006, p. 364) alerta: "[...] não se explicar demais". Só assim é possível amainar o ponto de vista autoral e perceber que uma mesma experiência de realidade é atravessada por diversos pontos de vista que se cruzam de modo tão intenso que só deixam passar forças, onde o registro da autoria não alcança.

Neste plano, onde a escrita só deixa passar forças, correm as palavras de fuga, mas mesmo aí, é impossível abrir mão das palavras de ordem, pois são elas que edificam a experiência da escrita. Todavia, por entre as estruturas porosas e solventes deste edifício, atravessam as palavras de fuga, como movimentos de variação da própria linguagem que rompem o ciclo de obrigação instalado pelas palavras de ordem. Como desdobramento deste rompimento, as palavras de fuga abrem caminho para a emergência de novas realidades (DELEUZE; GUATTARI, 1995).

A "escrita de si" precisa descobrir canais para fazer valer em sua edificação a potência de dissolução promovida pelas palavras de fuga. Do contrário, a escrita é capturada pelo traço fálico da autoria. Para tanto, o escritor precisa mergulhar em um plano de dissolução, onde as certezas que leva consigo são dissolvidas.

Tal mergulho não se faz sem acionar a memória inventiva. Segundo Deleuze (2006), a memória pode ser tanto rememorativa quanto inventiva. Enquanto a primeira opera "termos e lugares fixos", a segunda compreende "essencialmente o deslocamento e o disfarce": 
Uma é estática, a outra é dinâmica. Uma é em extensão, a outra é intensiva. Uma é ordinária, a outra é notável e repetição de singularidades. Uma é horizontal, a outra é vertical. Uma é desenvolvida, e deve ser explicada; a outra é envolvida, e deve ser interpretada [...] Uma é de exatidão e de mecanismo, a outra é de seleção e de liberdade. Uma é repetição nua, que só pode ser mascarada por acréscimo e posteriormente; a outra é repetição vestida, cujas máscaras, deslocamentos e disfarces são os primeiros, os últimos e os únicos elementos. (DELEUZE, 2006, p. 396).

É no espaço dinâmico e intensivo onde a memória inventiva se aninha e estende seus domínios, que um novo mergulho na experiência pode ser forjado, abrindo espaços para a dissolução do humano na escrita e para as trilhas desbravadas pela "escrita de si".

\section{A DISSOLUÇÃO DO HUMANO NA ESCRITA}

Para entender do que se trata esta dissolução recorremos aos estudos de Lourau (1998) sobre a dissolução do humano na escrita. Segundo este autor, a dissolução abranda as pretensões coercivas da identidade - inscrita na centralidade do sujeito, no plano pessoal permitindo um acolhimento do outro e as variações da experiência. Nesta dissolução, a escrita comporta variações de velocidade que permitem a abertura a uma narrativa operada em uma espécie de transe.

Lourau (1998) chama este exercício narrativo mobilizado pela dissolução do humano de escrita automática. Sob os domínios da escrita automática, o escritor experimenta o limite da consciência de si. Disso decorre que o traço da escrita não se engendra sob a ótica de um ponto de vista, não se enquadra como um relato representativo sobre uma experiência vivida e tampouco pretende dizer algo sobre ela. $\mathrm{E}$ isso tudo revela um traço muito peculiar a esta prática: não está em jogo na escrita automática o quanto de verdade pode suportar um olhar que pretendeu falar sobre certa experiência vivida. Não se trata, portanto, de fundar uma verdade e 
instituí-la como discurso representante de certo acontecimento considerado na escrita, mas de desempenhar um conhecimento, colocando-o à prova, seguindo os rastros de um encontro essencial que reclamou pela mobilização do conhecimento, lá no momento mesmo em que o acontecimento se deu como evento.

Como é possível um dizer que não se coloca sobre a experiência vivida? O discurso irônico, corrente nos estudos de Nietzsche e Foucault, pode inspirar possibilidades de resposta a esta questão.

Aquele que escreve com ironia - aponta Albuquerque Júnior, a partir de sua leitura dos estudos de Nietzsche e Foucault (2008, p. 100) - [...] sabe que o que diz não é propriamente o que a coisa é e sabe que a coisa nunca é aquilo de que dela se diz. As palavras nunca dão conta de revelar a verdade das coisas e estas sempre estão em excesso em relação àqueles conceitos que as pretende definir.

Neste sentido, o irônico desmonta as supostas versões verdadeiras que encontra pelo caminho, mostrando que elas não passam de fabricações históricas tecidas por olhares crentes e dogmáticos, que anseiam por seu brilho eterno no pilar das verdades ditas.

O irônico tece sua narrativa longe da acomodação de um lugar, pois aí a sedução de uma verdade, a saber, facilmente o localiza e o faz sucumbir a seus domínios. Afinal, a busca da verdade é uma tarefa sedutora, já dizia Nietzsche $(2003,2008)$. Ter uma verdade a ser dita é sinal de poder. O irônico, no entanto - acometido por uma curiosidade mobilizante - ousa esnobar desta modalidade de poder, lhe dá as costas, na busca de um não-lugar que o distancia da norma, da ordem e dos lugares estabelecidos e valorizados positivamente. E, desta não-localidade faz a experiência da escrita: uma escrita que já não é mais sua, pois é não-local, tecida na fronteira, nos limites de um si fora de si. 
Segundo Souza (2008), a escrita nos limites de um si fora de si coloca o escritor frente ao abismo da escritura. A escritura em abismo abriga um pensamento que só se constitui em cena e como tal, está sempre 'por fazer'. Realça-se assim, a figura de um escritor em movimento, que se insinua na textualidade - na ordem estabelecida pelo discurso - e nela se faz ausente, abandonando-a "[... absolutamente às vicissitudes de um pensar que não precede, mas que é concomitante ao ato da escritura." Desta maneira a escritura vai constituindo um dizer que, "[...] sem preestabelecer o que há a ser dito, deixa aparecer um saber sem sujeito." (2008, p. 209).

\section{Considerações Finas}

Para além das competências teóricas, o espaço da "escrita de si" ajuda a edificar uma compreensão para além da superfície a respeito da formação profissional, não porque dispara um discurso sobre a prática, mas por dar vazão à escrita das intensidades forjadas nos encontros entre conhecimento e prática/pesquisa.

Ao lidar com o corpo em movimento, o profissional de Educação Física encontra espaço privilegiado para potencializar o exercício da escrita, pois é o movimento que expõe o profissional à experiência, lançando-o ao jogo, frente ao encontro com as demandas em ato. Assim, se não há movimento não há jogo: não há prática profissional.

Segundo Deleuze (2006, p. 93) o movimento "[...] implica uma pluralidade de centros, uma superposição de perspectivas, uma imbricação de pontos de vista, uma coexistência de momentos que deformam essencialmente a representação." A partir desta idéia é possível entender o movimento como elemento transgressor do conhecimento, que dá testemunho das potências que correm sob as teorias conhecidas, na mobilização operada na prática profissional. Ao trabalhar com o corpo em movimento, o profissional de Educação 
Física se depara com esta potência transgressora e, mesmo que a descarte quando se propõe pensar sobre sua prática, ela é irredutível no campo da experiência vivida 9 .

O corpo em movimento vaza à ordem dos discursos que pretender dizer algo sobre ele no campo da objetividade científica. O profissional de Educação Física experimenta este vazamento quando percebe que muitas situações que vivencia são reduzidas e resumidas dentro do enquadramento da escrita acadêmica. $\mathrm{O}$ discurso científico não suporta a pluralidade e singularidade dos acontecimentos e é justamente por isto que os enquadra em uma ordem de conhecimento devida. A experiência, portanto, enquanto encontro, alerta o profissional de que nem tudo é dado a conhecer. $\mathrm{O}$ que escapa à ordem do conhecimento atravessa os campos da sensibilidade, aguçando as percepções dos envolvidos no encontro instalado.

A sensibilidade não é da ordem da competência, portanto não pode ser dada à priori como algo a conhecer. Embora tradicionalmente a formação profissional em Educação Física não tenha se ocupado como aquilo que escapa à ordem da competência, o profissional atuante acaba por encontrar seus próprios caminhos quando se lança ao exercício da profissão. Muitos encontram diálogo entre o conhecimento e a sensibilidade despertada na prática quando se permitem organizar, sistematizar, ou ainda documentar suas vivências nos chamados relatos de experiência.

A escrita dos relatos é potencialmente transgressora, ou, pelo menos, deveria ser, pois antes de se acomodar enquanto registro de reiteração, os relatos são impressões de um movimento experimentado e, enquanto tais, desestabilizam o conhecimento. A idéia de movimento forjada por Deleuze (2006) nos inspira a pensar

\footnotetext{
${ }^{9}$ Historicamente a área denominada Educação Física pauta suas discussões, predominantemente, a partir de um ideal de inteligibilidade, operado por pressupostos objetivistas e cientificistas. $O$ legado desta tradição afeta não somente a produção de conhecimentos, mas, sobretudo, a prática profissional. Todavia, a experiência sempre aponta para a possibilidade de transgressão desta ordem histórica e é justamente neste espaço e tempo que se agregam as pesquisas qualitativas e os diálogos que a área se permite junto ao campo das ciências humanas e sociais (ALVES, 2009).
} 
que os relatos podem registrar os modos através dos quais o escritor se colocou no jogo entre a prática e o conhecimento. Os relatos, portanto, são exercícios que trazem as marcas da transgressão, dos pontos de fuga, de invenção e ousadia daquele que se lança ao exercício profissional.

Estas marcas da transgressão registradas nos relatos despertam o espírito questionador daquele que se dobra a leitura destes registros, pois o movimento que operam contagia o leitor, movendo-o também. $\mathrm{E}$, neste plano, o relato de experiência se aproxima das intensidades ensaiadas no exercício da "escrita de si".

De fato, não é fácil imprimir as intensidades da experiência no campo da escrita, mas, se lançar ao permanente aprendizado, em processos de formação abertos a experiência dessa qualidade da escrita, pode ser um caminho. Dobrar a atenção sobre as profundidades reveladas na "escrita de si" significa pensar a própria formação como um exercício de cultivo, que vai além de um período determinado, para se implicar na constituição da própria vida. E, isso também significaria a propagação indefinida da "escrita de si". 
The "Self-writing" on the formation in Physical Education

Abstract: The objective of this article is to create a field of quarrels about "Self-writing" on the context of professional graduation in Physical Education, recognizing this writing exercise as a potential way to find what escapes to the knowledge terms and that force the thought to think the consistency of the meeting that across the graduation process. From this point, we want to reach the demands that are excluded in the formation speech - the demands of sensibility recognizing them as expressions of an "incarnate knowledge". Beyond the theoretical skills, the "Selfwriting" helps us to build a deeper understanding of the professional graduation, not because it play on a speech upon the practices, but for giving opening to the writing of the intensities forged in the meeting between practice and knowledge - where the professional intervention is installs.

Keywords: Physical Education. knowledge. Professional performance. Abilities.

\section{La "Escritura del si" en la formacíon en Educación Física}

Resumén: El objetivo de este ensayo es crear un campo de peleas sobre la "escritura del si" en el contexto de la formación profesional en la Educación Física, reconociendo este ejercicio de la escritura como una manera potencial de encontrar aquilo qué se escapa a la órden del conocimiento y qué fuerza el pensamiento para pensar la consistencia del la reunión que cruza el proceso de la formación. Del este punto, queremos alcanzar las demandas que quedan excluydas del discurso de la formación - las demandas de la sensibilidad - reconociéndolas como expresiones de un "conocimiento encarnado". Más allá de las habilidades teóricas, la "escritura del si" ayuda nosotros el la contrución del una comprensión más profunda de la formación profesional, no porque dispara un discurso sobre las prácticas, pero por dar abertura a la escritura de las intensidades forjadas en la reunión entre la práctica y el conocimiento - donde el juego del la intervención profesional es instalado.

Palabras clave: Educación Fisica. conocimiento; Atuación profesional. Competencias. 


\section{REFERÊNCIAS}

ALBUQUERQUE JÚNIOR, Durval Muniz. Foucault e a Mona Lisa ou Como escrever a história com um sorriso nos lábios. In: RAGO, Margareth; VEIGA-NETO, Alfredo (Org.). Figuras de Foucault. Belo Horizonte: Autêntica, 2008. p. 97-107.

ALVES, Flávio Soares. Pesquisa Qualitativa: desbravando territórios possíveis de se fazer ciência na Educação Física. Motriz, Rio Claro, v. 15, n. 4, p. 955-963. 2009.

DELEUZE, Gilles. Diferença e Repetição. Rio de Janeiro: Graal, 2006

DELEUZE, Gilles. Mil Platôs: capitalismo e esquizofrenia. São Paulo: Ed. 34, 1995. v.2.

DELEUZE, Gilles; PARNET, Claire. Diálogos. Trad. Eloísa Araújo Ribeiro. São Paulo: Escuta, 1998.

FOUCAULT, Michel. A escrita de si. In: FOUCAULT, Michel. Ditos e Escritos: Ética, Sexualidade, Política. 2.ed. Rio de Janeiro: Forense Universitária, 2006. v.5, p. 144162.

IMBERNÓN, Francisco. Formação Docente e Profissional: formar-se para a mudança e a incerteza. São Paulo: Cortez, 2010.

KASTRUP, Virgínia O Funcionamento da atenção no trabalho do cartógrafo. In: PASSOS, Eduardo; KASTRUP, Virgínia; ESCÓSSIA, Liliana (orgs.). Pesquisaintervenção e produção de subjetividade. Porto Alegre: Sulina, 2009. p. 3251.

LOURAU, Rene. Análise institucional práticas de pesquisa. Rio de Janeiro: UERJ, 1993.

LOURAU, Rene. L'écriture automatiqu: Les Cahiers de l'implication. Revue d'analyse Institutionnelle, Saint-Denis, n. 2, p. 35-38, 1998.

LOURAU, Rene. A análise institucional. Petrópolis, Rio de Janeiro: Vozes, 1996.

NIETZSCHE, Friedrich. A vontade de Poder. Rio de Janeiro: Contraponto, 2008.

NIETZSCHE, Friedrich. Ecce Homo. São Paulo: Martin Claret, 2003.

PASSOS, Eduardo; KASTRUP, Virgínia; ESCÓSSIA, Liliana (orgs.). Pesquisaintervenção e produção de subjetividade. Porto Alegre: Sulina, 2009.

SOUZA de Pedro O sujeito fora de si: movimentos híbridos de subjetivação na escrita foucautiana. In: RAGO, Margareth; VEIGA-NETO, Alfredo (Org.). Figuras de Foucault. Belo Horizonte: Autêntica, 2008. p. 205-214. 
Endereço para correspondência:

Flávio Soares Alves

Rua: Domingão Gonçalves, 109 - Vila dos Lavradores

Botucatu - São Paulo

CEP: 18609-057

Recebido em: 9.5.2010

Aprovado em: 19.06.2011

Movimento, Porto Alegre, v. 17, n. 02, p. 239-258, abr/jun de 2011. 
